\title{
'Living' wage, class conflict and ethnic strife
}

\author{
Indraneel Dasgupta ${ }^{\bullet}$
}

School of Economics, University of Nottingham, University Park, Nottingham NG7 2RD, UK

Phone: 44-115-9514297 Fax: 44-115-9514159 E-Mail: indraneel.dasgupta@nottingham.ac.uk

Version: 2 August 2008

\begin{abstract}
:
We examine how group-specific differences in reservation wage, arising due to asymmetries in social entitlements, impact on distribution via the joint determination of class conflict between workers and employers, and 'ethnic' conflict among workers. We model a twodimensional contest, where two unions, representing different sections of workers, jointly but non-cooperatively invest resources against employers in enforcing an exogenously given rent, while also contesting one another. The rent arises from a 'living' wage, set above reservation wage rates via labour regulations. We show that high reservation wage workers gain, and employers lose, from better social entitlements for low reservation wage workers. The latter however benefit, with employers and against the former, from weak labour regulations. When minority/immigrant workers are marginalized both in the labour market and in nonwage entitlements, improving job access and expanding 'social support' has contradictory effects on class and ethnic conflicts. 'Trade unionism', i.e. political articulation of shared economic interests alone, appears insufficient to temper ethnic conflicts among workers.
\end{abstract}

Keywords and Phrases: Class conflict, Ethnic conflict, Living wage, Labour regulation, Social entitlement, Affirmative action, Distribution.

JEL Classification Numbers: D31, D72, D74, I38, J52, O17.

\footnotetext{
- I thank Ravi Kanbur for numerous conversations over the years on issues related to this paper.
} 


\section{Introduction}

Conflict between workers across ethnic or religious divides is typically perceived as reducing their collective strength as a class in the common distributive conflict against employers. ${ }^{1}$ The key strategic question frequently facing political formations on the Left is thus how class unity among workers may be achieved in practice. At the same time, greater mobilization of workers in their common economic conflict against employers is also often considered an effective barricade against ethnic conflict within the working class. The idea appears to be that the very provision of a political platform for articulating common economic interests of workers would serve to reduce conflicts within the working class along identity fault-lines, by revealing to them the ultimately self-defeating consequences of such 'fratricidal' warfare. ${ }^{2}$ Yet, in practice, attacks on one section of workers by another are often sought to be legitimized by the argument that the former are objectively advancing the interests of employers against those of the working class as a whole. Thus, for example, during the anti-immigrant riots in South Africa in May 2008, Black South Africans involved in the violence were reported as accusing foreigners of undoing years of fighting against white rule and undermining the minimum wage. ${ }^{3}$ Differences in reservation wage rates between native and immigrant workers impacted on both class conflict between workers and employers and ethnic conflict among workers: these two dimensions of distributive conflict in turn conditioned one another.

Individuals often acquire a quantum of resources purely by virtue of their membership of some collectivity. Identity divisions among workers, in conditions where they acquire political salience, also often largely overlap with historically generated differences in such 'social' (i.e., nonmarket) entitlements. Social entitlements in turn determine the terms under which an individual is willing to sell her labour power in the industrial economy, i.e. her reservation wage. Workers from communities with lower social entitlements typically have a lower reservation wage. The primary objective of working class organizations in the economic conflict against employers is to ensure a greater surplus for workers, i.e., a higher premium over the reservation wage. Yet, the same wage rate

${ }^{1}$ Lenin's 1905 address to Jewish workers in Russia provides a clear, and oft-cited, articulation: “(T)he Jewish workers, as a disenfranchised nationality, not only suffer general economic and political oppression, but they also suffer under the yoke which deprives them of the elementary civil rights. The heavier this yoke, the greater the need for the closest possible unity among the proletarians of the different nationalities; for without such unity a victorious struggle against the general oppression is impossible” (Lenin, 1986: p. 42).

${ }^{2}$ For example, Barack Obama attempted to trump racial divisions with a call to working class unity during his 2008 US Presidential campaign: “(T)his time we want to talk about the fact that the real problem is not that someone who doesn't look like you might take your job; it's that the corporation you work for will ship it overseas for nothing more than a profit” (Speech in Philadelphia; The Guardian, London, 18 March 2008).

3 “Other locals expressed anger, arguing that Africans from neighbouring countries were prepared to work for only $\$ 4$ a day when they insist on a minimum wage of at least $\$ 12$. They were also angry with white South Africans who employ foreigners for what they say is next to nothing. Responding to the charge that black South Africans are lazy and unwilling to work as hard as their poorer neighbours and were chasing away the competition, the group asked why they should have to toil for so little or be poor in a country rich with diamonds and gold” (“S Africa violence reaches Cape Town”: Al Jazeera English, 23 May 2008, http://english.aljazeera.net/). 
implies differential premiums for workers across identity divides, when such divides overlap, due to historical reasons, with present differences in reservation wage.

The purpose of this paper is therefore to examine how ethnicity or religion-specific differences in reservation wage, interpreted as the consequence of historically generated asymmetries in social entitlements, impact on distribution via the joint determination of class conflict between the working class and the employing class, and 'ethnic' conflict (i.e., distributive conflict along such identity divides) within the working class. Does prior inequality in social entitlements within the working class end up harming even its privileged section? Would higher returns from engaging in class conflict reduce ethnic conflict or benefit all workers? Can 'trade-union politics', i.e. articulation of shared economic interests in contesting the employing class, suffice as an incentive for rational workers to abjure intra-class warfare? These are the questions we address. ${ }^{4}$

The connection between identity divides and asymmetries in social entitlements (and thus reservation wage) among different segments of workers that we highlight arises in many different contexts. Jewish workers in Europe in the $19^{\text {th }}$ and early $20^{\text {th }}$ centuries, Arab workers in Israel, Black workers in apartheid South Africa, Black workers in Jim Crow US, lower-caste workers in India, all provide obvious examples of segments systematically denied access to residential neighbourhoods and valuable public facilities, including security, that are available to other segments of the working class. ${ }^{5}$ In many developing societies, customary rights to rural common property resources such as forests, rivers, ponds, grazing land, and sometimes even small plots for subsistence agriculture, are contingent on being born into specific ethnic or religious groups. In most countries, large sections of immigrant workers face legal restrictions on accessing health, welfare and educational facilities, relative to the native-born. Furthermore, ethnic and religious communities often develop their own support institutions which largely, or even entirely, exclude other communities. Thus, workers from communities with weaker internal support institutions find themselves with lower social entitlements.

There is a second sense in which differences in community origin may generate differences in social entitlements. Modern large-scale production develops by absorbing, as workers, individuals from traditional forms of employment in subsistence agriculture, artisanal production, petty trade and services. ${ }^{6}$ Different ethnic or religious groups have often specialized in specific niche occupations in pre-modern societies. Entry into these occupations was regulated by a mix of custom, traditional law and competitive advantage due to inter-generational transmission of information and training

4 Roemer et al. (2007) have shown how ethnic divisions may lead to electoral equilibria which restrain redistribution. We focus instead on non-electoral conflict equilibria. Thus, our contribution is rooted in the literature on conflict and rent-seeking contests (see Garfinkel and Skaperdas, 2007, for a survey). In this literature, Katz and Tokatlidu (1996) and Glazer (2002) analyse aspects of internal vs. external rent seeking. While sharing a structural analogy, our specific focus is different. Dasgupta and Kanbur (2007, 2005a) examine the mediation of ethnic and class conflicts through voluntary contribution to public goods that are valued independently of income consequences. We complement their analysis by abstracting from such public goods.

5 See Dasgupta and Kanbur (2005b) for an expanded discussion of how community origin may influence access to public goods.

${ }^{6}$ As in the classical two-sector model of economic development due to Lewis (1954). 
exclusively within the community. Thus, in developing societies today, it is not unusual to find different traditional occupations generating different earnings, yet being largely dominated by particular identity groups. The modern industrial economy expands in these societies by drawing in, as similarly paid workers, individuals whose earning opportunities in the residual, traditional/informal sector can vary greatly depending on their ethnic location. ${ }^{7}$

While conflict between workers and employers has various dimensions, we focus on such conflict over the scope and implementation of a given, legislatively sanctioned 'social/living wage'. While the notion of 'social entitlement' involves the rights of individuals to a quantum of resources purely by virtue of their membership of some community, that of a 'social' wage involves a collective recognition of an individual's right to a quantum of resources merely on account of her willingness to alienate her labour power. Minimum wage laws constitute the obvious example of social regulation of the employment relationship. But the notion of a social wage also includes regulation of other aspects such as workers' health and safety, hours of work, leave and childcare facilities, minimum age of employment etc. Together, such labour regulations aim to put a composite floor on an individual's return from selling her labour power, above what an uncontrolled labour market might typically provide. This composite floor, the social wage, thus generates a rent, which is contested over by workers and employers. While unions seek to enforce and expand the scope of the social wage, employers attempt to restrict or evade it, whether illegally or by utilizing loopholes and ambiguities in legislation. Much of the day-to-day conflict between employers and unions takes the form of such contestation. It is this aspect of the class conflict, and its relation to ethnic conflicts among workers over sharing of the associated rent accruing to the working class as a whole, which we analyze.

We model a two-dimensional contest, where two agents (unions), representing different sections of workers, jointly but non-cooperatively invest resources against employers in acquiring a share of an exogenously given rent, or surplus. This surplus arises from an exogenously determined social wage, set above workers' reservation wage rates. Employers seek to evade the social wage and pay workers their reservation wage, whereas the unions attempt to defend (i.e. enforce) it. The two sections of workers, interpreted as two different identity groups, differ in terms of their reservation wage. The two unions also invest resources in a simultaneous contest against one another that determines how the surplus accruing to the working class is divided between its constituent sections. An agent representing employers chooses their resource expenditure on evading the social wage, taking into account the equilibrium defensive responses of the two unions. Thus, ethnic conflict within the working class and class conflict between workers and employers jointly determine the distribution of the surplus among employers and the two constituent sections of the working class.

7 In India, for example, caste and religious groups typically continue to dominate in their respective traditional occupations, generating systematic differences in earnings across communities. See, for example, Harris-White (2003). Ethnic niches are not absent even in the modern sector, and capitalists may find it rational to wage discriminate among workers belonging to different ethnic groups (e.g. Roemer, 1979). Our interest however lies in analyzing ethnic conflicts among workers even when they are treated identically by capitalists. 
We first show that the union representing 'advanced' workers, i.e., workers with high reservation wage, may concentrate exclusively on ethnic contestation against other workers, choosing to leave class contestation entirely to the union representing 'backward' workers, i.e. workers with low reservation wage. The latter participates in both ethnic and class warfare. We then show that a rise in the reservation wage of backward workers also benefits advanced workers, while hurting employers. Such a rise reduces the incentive for the backward section to invest in either class or ethnic conflict, thereby increasing both employer evasion and the share of the advanced section. For advanced workers, the second (ethnic) effect necessarily dominates the first (class) effect, so that this section benefits overall. For employers, lower gain from successful evasion outweighs the benefits from greater evasion, so that their income falls overall. A rise in the social wage, while aggravating both class and ethnic conflicts, benefits only the advanced section of the working class, making the backward section and employers both worse off. These comparative static conclusions regarding conflict and distribution hold even when backward workers do not compete with advanced workers in large sectors of the labour market, say due to discrimination, legal restrictions, or small numbers.

Our exploration suggests that advanced workers may, indirectly, benefit from improved social entitlements for backward workers. Thus, we provide micro-foundations for an argument of class solidarity between advanced and backward workers, grounded in an 'enlightened' (i.e. general equilibrium) conception of self interest. However, our analysis also suggests that such an argument may be difficult to extend beyond the sphere of social entitlements to that of 'labour rights'. Specifically, our results suggest that working class (say minority or immigrant) communities with weak entitlements may share an interest, with employers and against workers from privileged communities, in keeping labour regulations (and thus the social wage) relatively low. Affirmative action programs that seek to open up larger sections of the labour market to workers from marginalized ethnic, racial or religious communities may pit such groups against workers from the dominant community, benefiting employers. Thus, when ethnic minority or immigrant workers are initially marginalized both in the labour market and in access to non-wage entitlements, improving job access (say, through positive discriminatory job quotas) and expanding 'social enfranchisement' (say, through improved housing, health, child-support and unemployment benefits) for such workers may have contradictory effects on class and ethnic conflicts. Lastly, our analysis suggests that the politics of 'trade unionism', i.e. articulation of shared objective economic interests alone, may prove insufficient to control ethnic conflicts within the working class. A working class politics that also ventures into the provisioning of class-cultural public goods, i.e. of non-economic forms of shared identity articulation specific to the working class as a whole, may have better prospects.

Section 2 develops the model. The main results regarding conflict and distribution are presented in Section 3. Section 4 discusses their extension to contexts where backward workers are prevented from competing in parts of the labour market. Section 5 summarizes and concludes. 


\section{The model}

Consider a society with two classes: employers (R) and workers (K). R controls access to a productive asset, say land or capital. This productive asset, when combined with one unit of labour, yields a revenue $\bar{W} \cdot{ }^{8} \mathrm{~K}$ is endowed with two units of labour power, but $\mathrm{R}$ does not own any labour power. Hence, $\mathrm{R}$ needs to employ half of K's labour power to generate the (gross) revenue $\bar{W}$; it retains the surplus left after wage payments. $\mathrm{K}$ is equally divided into 'advanced' (M) and 'backward' (B) sections, distinguished by different reservation wage rates, respectively, $w_{M}$ and $w_{B}$; $\bar{W}>w_{M}>w_{B} \geq 0$. We interpret these two sections as different identity (ethnic or religious) groups. Workers can be hired at some 'social' (exogenously mandated, and thus non-market clearing) wage rate $W \in\left[w_{M}, \bar{W}\right]$. This social wage rate is however 'contested', in that employers attempt to attack (evade) it by hiring only B workers and paying them $w_{B}$, whereas workers seek to defend (enforce) the social wage. The extent of implementation of the social wage is thus determined as the outcome of class conflict between workers and employers.

To fix ideas, we think of the social wage as a legislatively mandated 'minimum' or 'living' wage, along with a package of mandated workers' benefits or 'protection' (e.g. pensions, severance payments, workplace voice and control, health and safety regulations, leave and childcare facilities, limitations on hours, intensity and forms of work, seniority and overtime rules, minimum age of employment, etc.). Typically, in practice, the social wage comes about as the legislative outcome of a complex and evolving process of society-wide political conflict and negotiation among representatives of workers, capitalists and others, including, historically, the landed gentry. ${ }^{9}$ These conflicts and negotiations may also have trans-national dimensions, in that international agreements often impose social wage conditions on participating countries. ${ }^{10}$ Once determined, the social wage generates a rent, which is contested over by workers and employers. It is this subsequent contestation that we wish to conceptually isolate and analyze. Such contestation can take both legal and extralegal forms. Laws leave loopholes, grey areas and interpretative ambiguities that are fought over in courts by representatives of employers and unions. Employers may also resort to illegal violation of labour regulations. ${ }^{11}$ Contestation can involve litigation, lobbying, bribing of judges, regulators and politicians, strike making and strike breaking activities (including the strategic use of violence), etc.

8 The assumption of inelastic labour demand can be relaxed without adding any substantive insight.

9 Conservative foundations for the welfare state were laid down in the $19^{\text {th }}$ century by Disraeli in Britain and Bismarck in Germany. Support or opposition from groups representing the peasantry, urban intellectuals, and the intermediate strata consisting mainly of petty traders, artisans and shopkeepers played a key role in the legislative evolution of labour regulations in most countries in the $20^{\text {th }}$ century.

10 The European Union imposes a set of labour regulations on all member countries. International trade, aid and investment agreements often include clauses regarding 'fair' labour standards/practices.

11 For example, Indian firms with fewer than ten workers are not subject to labour regulations, while most large firms maintain a substantial casual labour force that is undeclared and thus free from regulation. The government is currently proposing to restrict the scope of labour regulations further, to firms employing more than forty workers. Violation of labour regulations is routine in developing countries. See Dasgupta and Marjit 
In the context of developing countries, one can site the social wage in the so-called formal (or modern, large-scale industrial) sector. Unions are, by and large, confined to this sector; minimum wage laws and other labour regulations also usually pertain only to this sector.

Each section of $\mathrm{K}$ is represented by its own union. The two unions, $\mathrm{M}$ and $\mathrm{B}$, noncooperatively spend resources, respectively $h_{M}, h_{B}$, to defend the social wage. Employers' spending on attacks on the social wage is $h_{R}$. We identify the extent of class conflict with overall expenditure on contestation over the social wage: $h \equiv h_{M}+h_{B}+h_{R}$. If class conflict occurs $(h>0)$, the proportion of workers hired who receive $W$ (working class success in the class conflict) is given by the Tullock $(1967,1980)$ contest success function $\left[\frac{h_{M}+h_{B}}{h}\right]$. The proportion of workers hired who receive $w_{B}$ is thus $\left[\frac{h_{R}}{h}\right]$. In the absence of class conflict $(h=0)$, this proportion is $\frac{1}{2}$.

There are different ways of interpreting our formulation of working class representation. One can visualize this in terms of separate and openly competing organizations divided along ethnic, religious or linguistic lines. One can also interpret it in terms of internally cohesive identity factions or even organizationally recognized sub-sections within a nominally united workers’ organization. ${ }^{12}$ The key idea that we seek to capture is that coordination costs of engaging in collective action are significantly lower within an identity group than across identity groups inside the working class. Class conflict involves attempts to ensure that all workers employed receive the social wage. Such attempts leave open the issue of how the consequent high (social) wage jobs will be rationed. This involves a second, 'ethnic' dimension to distributive conflict, which we now formally model. ${ }^{13}$

Each union seeks to ensure a greater share of available high (social) wage jobs for its own section of the working class. Expenditures on such 'ethnic' contestation are denoted by $g_{M}, g_{B}$. We identify the extent of ethnic conflict with overall expenditure on contestation over the social wage

(2006) for a discussion and a model of class conflict in such a setting. A recent British Trades Union Congress Report on Vulnerable Employment claims that more than two million people in Britain endure $19^{\text {th }}$ century workplace practices, including payments below the minimum wage, absence of paid holiday or sickness leave, exceptionally long hours, and no compensation for workplace injuries. The report argues much exploitative treatment occurs because of legal loopholes that employers utilize (Trades Union Congress, 2008). The Report itself provides an example of expenditure by trade unions to contest and restrict such loopholes. Ehrenreich (2001) documents similar practices in the US, where union-busting constitutes a multi-billion dollar industry.

12 In India, for example, central trade unions affiliated to the national political parties contain caste, religion or region-specific internal lobbies; a multitude of independent trade unions also exist which explicitly seek to represent workers from particular communities. Ethnic sub-sections formed the organizational building blocks of the trade union movement in the Austro-Hungarian empire, as well as late $19^{\text {th }}$ - early $20^{\text {th }}$ century US.

13 The de-linkage between contribution to class contestation and consequent gains typically arises due to indivisibilities in coverage and consequent non-excludability. Class contestation thus acquires a public good aspect: unions cannot prevent free-riding. For example, gains due to a strike cannot be restricted to participating workers, while enforcement of labour regulations cannot be confined to union members. Consequently, unions separately seek to ensure that their members constitute a larger proportion of the workers under coverage: such attempts bring about inter-union conflict. While the literature has widely noted the collective action problem in the context of individual unions, our intuitive entry-point is its exacerbation across ethnic/religious boundaries. 
within the working class: $g \equiv g_{M}+g_{B}$. Success in ethnic conflict is determined by relative expenditure: the share of social wage jobs that accrues to $M$ is $\frac{g_{M}}{g}$ if $g>0$, and $\frac{1}{2}$ otherwise. $^{14}$

Intuitively, we think of ethnic conflict within the working class, like class conflict, as having both legal-legislative and extra-legal manifestations. Ethnic conflict can involve the strategic use of violence against workers of a different identity group. Violence, intimidation, strike action and organization of consumer boycotts can also be used against employers to induce them to offer a greater share of available high wage jobs to workers from a particular identity group. Unions may lobby legislatures to pass or tighten laws restricting or enhancing access to high wage jobs for specific ethnic groups, through, say, ethnic hiring quotas, language requirements, immigration and residential restrictions, selective or preferential provision of job information, etc. All these activities necessitate the expenditure of resources: thus, for our purposes, they are treated as a composite whole.

Let $\Delta_{B} \equiv W-w_{B}, \Delta_{M} \equiv W-w_{M}, \Delta \equiv \frac{\Delta_{B}}{\Delta_{M}}$; and let $\pi_{j}$ denote the payoff (income) of agent $j ; j \in\{M, B, R\}$. These payoffs are then defined as follows.

$$
\begin{aligned}
& \pi_{B}=\Delta_{B}\left(\frac{h_{B}+h_{M}}{h}\right)\left(\frac{g_{B}}{g}\right)-g_{B}-h_{B}+w_{B} ; \\
& \pi_{M}=\Delta_{M}\left(\frac{h_{B}+h_{M}}{h}\right)\left(\frac{g_{M}}{g}\right)-g_{M}-h_{M}+w_{M} ; \\
& \pi_{R}=\Delta_{B}\left(\frac{h_{R}}{h}\right)-h_{R}+(\bar{W}-W) .
\end{aligned}
$$

$\mathrm{R}$ first decides how much resource to allocate to attacking the social wage, i.e., the size of $h_{R}$. The two unions subsequently, and simultaneously, decide how much resource to allocate to class and ethnic conflicts. Thus, the interaction between unions M and B is modelled as a Cournot game where the union $j \in\{M, B\}$ chooses its pair of conflict allocations $\left\langle g_{j}, h_{j}\right\rangle$, given the prior employing class conflict allocation $h_{R}$. This Cournot game is embedded within a framework of Stackelberg interaction between the employing class and the working class as a whole, with the former acting as the Stackelberg leader. In standard fashion, we shall solve this game via backward induction. ${ }^{15}$

14 Skaperdas (1996) provides an axiomatic generalization of the Tullock contest function. Our substantive conclusions will remain unchanged under his more general specification of the conflict technology. Assuming risk neutrality, contest success can also be interpreted in probabilistic terms, instead of job shares.

15 Katz and Tokatlidu (1996) model a general rent-seeking contest in two stages, where two internally homogeneous groups Cournot-contest a given rent in the first stage, and (identical) members of the winning group engage in mutual contestation in the subsequent stage. Our formulation, in terms of a Stackelberg leader contesting a group with two dissimilar members, who simultaneously engage in contesting the leader as well as one another, is quite different. Second, while Katz and Tokatlidu (1996) focus on how group size affects rentseeking expenditure, we examine how differences in reservation wage impact on conflict and distribution. 
Consider therefore first the interaction between the two unions, facing a predetermined social wage rate $(\mathrm{W})$ and employers' conflict allocation $\left(h_{R}\right)$. Recall the objective functions specified by (1)-(2). For $j \in\{M, B\}$, the decision problem is:

$$
\underset{h_{j}, g_{j}}{\operatorname{Max}} \pi_{j}=\Delta_{j}\left(\frac{h_{B}+h_{M}}{h}\right)\left(\frac{g_{j}}{g}\right)-g_{j}-h_{j}+w_{j} .
$$

In equilibrium, it must be the case that:

$$
\begin{aligned}
& \frac{\partial \pi_{B}}{\partial g_{B}}=\Delta_{B}\left(\frac{h_{B}+h_{M}}{h}\right)\left(\frac{g_{M}}{g^{2}}\right)-1 \leq 0, \\
& \frac{\partial \pi_{B}}{\partial h_{B}}=\Delta_{B}\left(\frac{h_{R}}{h^{2}}\right)\left(\frac{g_{B}}{g}\right)-1 \leq 0, \\
& \frac{\partial \pi_{M}}{\partial g_{M}}=\Delta_{M}\left(\frac{h_{B}+h_{M}}{h}\right)\left(\frac{g_{B}}{g^{2}}\right)-1 \leq 0, \\
& \frac{\partial \pi_{M}}{\partial h_{M}}=\Delta_{M}\left(\frac{h_{R}}{h^{2}}\right)\left(\frac{g_{M}}{g}\right)-1 \leq 0 .
\end{aligned}
$$

Proposition 1. In any Nash equilibrium, $h_{B}, g_{M}, g_{B}>0$, and $h_{M}=0$.

Proof: See the Appendix.

By Proposition 1, in a Nash equilibrium, only backward workers will contribute resources to defending the social wage. The advanced section will concentrate exclusively on ethnic contestation against other workers for a share of available high (social) wage jobs. Thus, both sections of the working class will engage in ethnic contestation, but the advanced section will free-ride on the backward section in the sphere of class contestation. This outcome is due essentially to fact that the net benefit (i.e., the rent) from employment at the social wage is lower for advanced workers, as their reservation wage is higher. For advanced workers to contribute to the class conflict, they must therefore be ensured a higher share of available high wage jobs. However, precisely because the net benefit from the social wage is higher for backward workers, the backward section will spend more on ethnic contestation, thereby ensuring a higher share for itself. Their weakness in ethnic contestation, itself a consequence of their privileged position (in terms of a higher reservation wage), will make the advanced workers unwilling to engage in class contestation against employers. ${ }^{16}$

16 To offer a suggestive illustration, the labour upsurge in the US in the 1890s was halted partly by the rise of anti-Catholic and anti-immigrant sentiments, led by the American Protective Association (a predominantly Scotch-Irish group) and the United American Mechanics. "Protestants were warned to avoid all unions dominated by papists, to discard the strike as a useless device, and to place no confidence in free silver. ... In the coalfields of Pennsylvania and Illinois this internecine strife checked a UMW organizing drive; in many cases it tore existing locals apart” (Higham, 1974: p.82). 
We now proceed to characterize the Nash equilibrium. Recall that $\Delta \equiv \frac{\Delta_{B}}{\Delta_{M}}>1$. Suppose an equilibrium exists. Then, from (4) and (6), in light of Proposition 1, we have:

$$
\begin{aligned}
& g=\Delta_{B}\left(\frac{h_{B}}{h}\right)\left[\frac{1}{1+\Delta}\right], \\
& g_{M}=\Delta_{B}\left(\frac{h_{B}}{h}\right)\left[\frac{1}{(1+\Delta)^{2}}\right], \\
& g_{B}=\Delta_{B}\left(\frac{h_{B}}{h}\right)\left[\frac{\Delta}{(1+\Delta)^{2}}\right] .
\end{aligned}
$$

Now, using (5), (8) and (10), and noting Proposition 1, we get:

$$
\Delta_{B}\left(\frac{h_{R}}{h}\right)\left[\frac{\Delta}{1+\Delta}\right]=h,
$$

so that, given any $h_{R}$, a Nash equilibrium must satisfy:

$$
\frac{h_{R}}{h}=\left[\frac{1+\Delta}{\Delta_{B} \Delta}\right]^{\frac{1}{2}} h_{R^{\frac{1}{2}}}
$$

Equation (11) represents the reaction function of the working class as a whole (K) faced by R. R chooses its optimal conflict expenditure taking into account the response of $\mathrm{K}$, as summarized by (11). Using (3) and (11), and assuming a Nash equilibrium exists, R's optimization problem is, therefore:

$$
\underset{h_{R}}{\operatorname{Max} \pi_{R}}=\left[\Delta_{B}\left(\frac{1+\Delta}{\Delta}\right)\right]^{\frac{1}{2}} h_{R}^{\frac{1}{2}}-h_{R}+(\bar{W}-W) .
$$

The first order condition yields the Nash equilibrium conflict expenditure of R:

$$
\vec{h}_{R}==\frac{\Delta_{B}}{4}\left[\frac{1+\Delta}{\Delta}\right] \text {. }
$$

Using (11) and (13), and recalling Proposition 1, we get the total equilibrium measure of class conflict as well as working class contribution to it:

$$
\begin{aligned}
& \vec{h}=\frac{\Delta_{B}}{2} \\
& \vec{h}_{B}=\frac{\Delta_{B}}{4}\left[\frac{\Delta-1}{\Delta}\right] .
\end{aligned}
$$

Notice that, by (14), class conflict does not exhaust the surplus $\left(\Delta_{B}\right)$. Together, (8)-(10) and (13)(15) yield the total equilibrium measure of ethnic conflict and its sectional contributions:

$$
\vec{g}=\frac{\Delta_{B}}{2}\left[\frac{\Delta-1}{(1+\Delta) \Delta}\right]
$$




$$
\begin{aligned}
& \vec{g}_{B}=\frac{\Delta_{B}}{2}\left[\frac{\Delta-1}{(1+\Delta)^{2}}\right] \\
& \vec{g}_{M}=\frac{\Delta_{B}}{2}\left[\frac{\Delta-1}{(1+\Delta)^{2} \Delta}\right] .
\end{aligned}
$$

In light of Proposition 1, equations (13), (15), (17) and (18) together completely characterize a Nash equilibrium if it exists. Evidently, the Nash equilibrium must be unique if it exists.

Notice that, from (14)-(15), we get the measure of equilibrium working class success in the class conflict, i.e. the proportion of workers hired who actually receive the social wage:

$$
\frac{\vec{h}_{B}}{\vec{h}}=\left[\frac{\Delta-1}{2 \Delta}\right] \in\left(0, \frac{1}{2}\right] .
$$

Analogously, from (16)-(17), we get the measure of the success of the backward section of the working class in ethnic conflict, i.e., its share of total social wage employment:

$$
\frac{\vec{g}_{B}}{\vec{g}}=\left[\frac{\Delta}{1+\Delta}\right] \in\left(\frac{1}{2}, 1\right] .
$$

By (20), the backward section is more successful in ethnic conflict than the advanced section. As discussed earlier, this is due to its rent from the social wage being higher. In turn, this outcome leads to the privileged section of workers withdrawing from the class conflict, as noted in Proposition 1.

Lastly, in light of (1)-(3), (13), (15), (17) and (18), equilibrium incomes are given by:

$$
\begin{aligned}
& \vec{\pi}_{M}=\frac{\Delta_{B}[\Delta-1]}{2 \Delta^{2}(1+\Delta)^{2}}+w_{M} ; \\
& \vec{\pi}_{R}=\frac{\Delta_{B}}{4}\left[\frac{1+\Delta}{\Delta}\right]+(\bar{W}-W) ; \\
& \vec{\pi}_{B}=\frac{\left[\Delta^{2}-1-2 \Delta\right][\Delta-1] \Delta_{B}}{4[1+\Delta]^{2} \Delta}+w_{B} .
\end{aligned}
$$

Notice that (23) implies $\vec{\pi}_{B}>w_{B}$ iff $\left[\Delta^{2}-1-2 \Delta\right]>0$. Since B can always ensure $w_{B}$ by choosing $\left[h_{B}=g_{B}=0\right]$, B must do so if $\left[\Delta^{2}-1-2 \Delta\right]<0$. However, by Proposition 1 , $\left[h_{B}=g_{B}=0\right]$ cannot constitute an equilibrium. Thus, an equilibrium exists in our model iff $\left[\Delta^{2}-1-2 \Delta\right] \geq 0$. We shall assume the inequality holds strictly, i.e., we shall assume:

A1. $\left[\Delta^{2}-1-2 \Delta\right]>0$.

A1 ensures the existence and uniqueness of the Nash equilibrium. A1 must hold when $\Delta$ is sufficiently large, i.e., when the advanced reservation wage is sufficiently higher than that of the backward segment. Thus, A1 implies $\Delta>2$, furthermore, A1 is necessarily satisfied when $\Delta \geq 2.5$. Note that, by (21)-(23), and given A1, M, B and R are all strictly better off by contesting. 


\section{Conflict and distribution}

We are now ready to specify how changes in reservation wage rates and the social wage impact on class and ethnic conflicts, and, thereby, distribution.

Proposition 2. Let A1 hold.

(i) A rise in the advanced reservation wage improves the success of the working class in the class conflict, while reducing ethnic conflict within the working class. The backward section is more successful in the ethnic conflict. Class conflict is unchanged.

(ii) A rise in the backward reservation wage reduces the success of the working class in the class conflict, while also reducing ethnic conflict within the working class. The backward section is less successful in the ethnic conflict. Class conflict falls.

Proof: See the Appendix.

A rise in the reservation wage of advanced workers reduces their rent from social wage jobs, thereby reducing their incentive to engage in appropriative activities against the backward section. This directly reduces aggregate expenditure on ethnic conflict. However, this relative withdrawal of the advanced section from ethnic contestation also induces the backward section to invest greater resources in defending the social wage. Consequently, employers' success in evading the social wage is reduced. This in turn elicits greater conflict within the working class. The direct effect nevertheless dominates, so that ethnic conflict falls overall (Proposition 2(i)). Thus, greater inequality in non-market entitlements serves to strengthen the working class in its conflict with employers, while also increasing the share of backward workers in high (social) wage jobs and reducing distributive tensions among workers. A rise in the reservation wage of backward workers reduces their net benefit from defending the social wage, inducing them to withdraw from both class and ethnic contestation. Such a rise also reduces the net benefit to employers from evading the social wage, leading to a fall in class conflict. The overall impact nevertheless is greater employer evasion of the social wage. The withdrawal of the backward section from ethnic conflict provides greater incentive to the advanced section to engage in ethnic contestation, but the former's withdrawal from the class conflict reduces such incentive. The net effect is both a fall in ethnic conflict and a relative strengthening of the advanced section. Thus, Proposition 2(ii) implies that an improvement in social entitlements for backward workers leads to greater evasion of the social wage and lower representation of backward workers in high wage jobs, though it mitigates both class conflict and ethnic conflict.

Remark 1. Total conflict expenditure $(h+g)$ can be viewed as a measure of aggregate conflict. By Proposition 2, a rise in the reservation wage of either section of workers reduces aggregate conflict. 
Proposition 2 characterizes how changes in reservation wages simultaneously impact on class and ethnic conflicts. We now proceed to specify their distributive consequences.

Proposition 3. Let A1 hold. Then, a rise in the reservation wage of either section of the working class makes the other section better off, and the employing class worse off.

Proof: See the Appendix.

By Proposition 2(i), higher reservation wage for advanced workers induces them to withdraw from ethnic contestation, thereby incentivising the backward section to invest more in the class conflict. Proposition 3 implies this offensive ensures greater surplus for the backward section, correspondingly reducing the income of the employing class. Conversely, a rise in the reservation wage of the backward section induces it to withdraw from both class and ethnic contestation (Proposition 2(ii)). The first (class) effect impacts the advanced section adversely; the second (ethnic) effect impacts it positively. Proposition 3 implies the ethnic effect dominates. Despite greater evasion, employers are worse off, since the rise in the backward reservation wage also reduces their gain from evasion.

By Proposition 3, an improvement in social entitlements for any section of workers, mediated through general equilibrium channels of class and ethnic contestation, also ends up benefiting the other section (while hurting employers). This suggests it may be in the objective economic interest of one section of the working class to support greater social entitlements for another. Notions of class solidarity may in this specific sense be objectively grounded in an 'enlightened' (i.e. general equilibrium) understanding of self interest, and advanced workers' opposition to greater social entitlements (say, in housing, education and health) for backward (say minority or immigrant) workers may perhaps be ascribed to 'false consciousness', 'racial prejudice' or employer propaganda.

However, the commonality of interest among workers in the sphere of social entitlement does not extend to the sphere of the social wage, as we now show.

Proposition 4. Let A1 hold. Then, a rise in the social wage reduces the success of the working class in the class conflict, while increasing both ethnic and class conflict. The backward section is less successful in the ethnic conflict. Advanced workers are better off, while both employers and backward workers are worse off.

Proof: See the Appendix.

A rise in the social wage, by increasing the prize, intensifies both class and ethnic conflict. Such a rise induces the advanced section to commit greater resources against the backward section, thereby reducing the latter's share of high wage jobs. This loss, in turn, weakens working class defence of the social wage, thereby inducing greater evasion by employers. Thus, Proposition 4 implies a rise in the social wage generates an offensive by both employers and advanced workers against backward 
workers. For the backward section, the negative impact of greater employer evasion and lower share outweighs the positive impact of the rise. ${ }^{17}$ Employers benefit from greater evasion, but achieve a lower surplus in case of successful working class defence. By Proposition 4, the second effect dominates. For advanced workers, greater success in ethnic contestation outweighs greater evasion by employers. Thus, advanced workers are the only beneficiaries of a higher social wage. Evidently, by Proposition 4, the optimal social wage from the backward workers' perspective is $w_{M}$.

In sum, Propositions 2, 3 and 4 together suggest that, while backward workers may share an interest with advanced workers against employers in improving their social entitlements, they may also share an interest with employers against advanced workers in keeping the social wage low.

\section{Extension: partially contestable labour markets}

In our analysis so far, we have assumed that the entire social wage employment is open to contestation by both sections of workers. In practice, it may be that different segments of the working class can directly compete with one another only in parts of the high wage labour market. For example, immigrant workers are often legally barred from applying for particular types of jobs, or kept beyond the pale of labour regulations. Affirmative action programs often take the form of hiring quotas for particular sections of workers, as in the case of caste-based reservations in India. One section of the working class may also be too small numerically to meet the entire labour demand at the social wage. Residential segregation, social discrimination or legal restrictions on travel and relocation may confine workers of a particular ethnicity to geographic pockets, so that they are unable to take up jobs too far outside those pockets. One can capture these situations in terms of some proportion, say $q \in(0,1]$, of available (i.e. enforced) social wage jobs being contested over by the two groups of workers, with the remaining proportion $(1-q)$ occupied exclusively by one group.

The conclusions presented earlier do not change if the backward section of workers can access a relatively high proportion of available social wage jobs (i.e., if either $q$ is close to 1 or the proportion $(1-q)$ is reserved for backward workers). However, if a sufficiently large proportion $(1-q)$ is reserved for advanced workers, so that the share of the labour market open to competition/contestation by backward workers, $q$, is sufficiently small, backward workers would withdraw completely from class contestation. The roles noted in Proposition 1 now get reversed, in that working class defence of the social wage is now carried out exclusively by advanced workers,

17 Glazer (2002) shows that the owner of a firm may be better off hiring a less productive worker, if she also happens to be less efficient in stealing from the owner. Our result, that backward workers are better off with a lower social wage, since this reduces 'stealing' by the advanced section, has a similar flavour. 
while both sections of workers continue to take part in ethnic contestation. ${ }^{18}$ This is a consequence of the fact that, as $q$ diminishes, the backward section's marginal benefit from class contestation falls, while that of the advanced section rises. A rise in the reservation wage of the backward section now comes to strengthen working class defence of the social wage, instead of weakening it (recall Proposition 2). Conversely, a rise in the reservation wage of the advanced section weakens working class defence of the social wage, instead of strengthening it. Thus, greater equality within the working class, in the sense of greater social entitlements for its backward section, serves to improve its success in the common conflict against employers only when the backward section is highly marginalized in terms of access to social wage jobs. As earlier (Proposition 3), a rise in the backward reservation wage benefits the advanced section, while hurting the employing class. Interestingly, however, a rise in the advanced reservation wage now comes to also benefit employers, by permitting greater evasion of the social wage. A rise in the social wage continues to increase the share of advanced workers in high wage jobs, as well as both class and ethnic conflict (as in Proposition 4). However, such a rise now comes to reduce employer evasion of the social wage. Employers thus doubly lose, while advanced workers doubly gain. Backward workers lose if the negative ethnic effect (lower share) outweighs the positive class effect (stronger enforcement).

Notice that improving access to employment on part of the backward section (formally, a marginal rise in $q$ from some initial value close to 0 ) leads to an aggravation of ethnic conflict, a relative withdrawal of the advanced section from the class conflict, and a consequent increase in employer evasion. ${ }^{19}$ As noted earlier, once $q$ crosses a critical threshold, the backward section

18 Formally, B now maximizes $\left[\pi_{B}=q \Delta_{B}\left(\frac{h_{B}+h_{M}}{h}\right)\left(\frac{g_{B}}{g}\right)-g_{B}-h_{B}+w_{B}\right]$, while M maximizes $\left[\pi_{M}=\Delta_{M}\left(\frac{h_{B}+h_{M}}{h}\right)\left[q\left(\frac{g_{M}}{g}\right)+(1-q)\right]-g_{M}-h_{M}+w_{M}\right]$. Since, in case of successful evasion, $\mathrm{R}$ is always better off by hiring a backward worker, R's objective function remains unchanged.

${ }^{19}$ US labour history serves to illustrate. At the beginning of WWII, Blacks had been excluded from defence jobs. After the 'March on Washington Movement' in 1941 by Black unionists, Roosevelt signed an executive order against job discrimination. Subsequently, Black workers obtained footholds in aircraft, vehicle assembly and ship-building. Between March and June 1943, over 100,000 man-days were lost in 'hate-strikes' by whites against the upgrading of Black workers. One of the largest occurred at the Packard Works in Detroit during April 1943, when 25,000 whites struck in retaliation for a brief sitdown of Blacks protesting their not being promoted. Two months later, Detroit erupted into anti-Black pogroms that took thirty-four lives (Cochran, 1977: pp. 221-223). In 1945, United Auto Workers leader Richard Frankensteen's predicted victory in his bid for the mayoralty of Detroit was denied by the defection of white auto workers protesting the CIO's endorsement of the federal Fair Employment Practices Committee. The next year, 'Operation Dixie' - the CIO's ambitious Southern organizing campaign, collapsed in the midst of racial conflict within the movement. After the 1955 reunification of the AFL and the CIO, the trade union leadership, in general, continued to exhibit “... benign neglect, if not overt racism, towards the plight of Black and Hispanic workers. ... (A)t the height of the anti-war and Black-power movements in 1968-70, the old-line craft unions, along with their allies in the Mafia-controlled teamsters and maritime unions, wrecked any hope of a New Deal-type social alliance by ... opposing schemes for Black control of local institutions (like the police or schools), rejecting demands for affirmative action in apprenticeship programs, and, in a majority of cases, aligning with the urban-Democratic anciens regimes against ghetto and campus demands, even frequently against newly unionized public-sector 
comes to replace the advanced section in the common conflict against employers. Then, further improvements in labour market access for the backward section (i.e. further rises in $q$ ) strengthen defence of the social wage, whereas improvements in their social entitlements weaken such defence.

\section{Discussion and concluding remarks}

Individuals typically acquire rights to a quantum of resources merely by virtue of their membership of some collectivity. These social entitlements determine the minimal terms under which individuals are willing to sell their labour power, i.e., reservation wage rates. Other rights pertain to the minimal terms under which employers may buy labour power. These 'labour rights', in the form of floor regulations on employers regarding wage, pensions, severance payments, workplace health and safety, leave and childcare facilities, limitations on hours and intensity of work, overtime rules, etc., aim to guarantee a composite ‘social/living' wage - a minimal return from selling one's labour power that is usually above what an unregulated market might provide. Social wage thus typically generates a rent, which is contested over by employers and workers. Much of the quotidian conflict between trade unions and employers' organizations can be viewed as the acting out of this contestation.

In heterogeneous societies, one's social entitlements, and thus one's reservation wage, often relate systematically to one's ethnic or religious community origins. It follows that organizations representing different communities of workers may differ in terms of their incentive to commit resources to enforcing the social wage. Additionally, such organizations have an incentive to ensure a greater share of available social wage employment for their own respective client communities. The conclusions generated by our formal analysis help to understand the general equilibrium interconnections between class conflict over enforcement of the social wage and ethnic conflict among different sections of workers over the sharing of available social wage employment.

Our analysis suggests that advanced workers may, indirectly, stand to benefit from greater social entitlements for backward workers. Thus, we provide some micro-foundations for an argument of class solidarity between advanced and backward workers, grounded in an 'enlightened' (i.e. general equilibrium) conception of self interest. However, our analysis also suggests that such an argument may be difficult to extend beyond the sphere of social entitlements to that of 'labour rights'. Specifically, our investigation suggests that working class (say minority or immigrant) communities with weak social entitlements may share an interest, with employers and against workers from communities with stronger social entitlements, in keeping labour regulations (and thus the social wage) relatively low. Additionally, affirmative action programs that seek to open up larger sections of the labour market to workers from marginalized ethnic, racial or religious communities may pit such groups against workers from the dominant community, benefiting employers in the process.

workers” (Davis, 1986: pp. 210-211). The AFL-CIO opposed racial quotas in hiring as a matter of principle. Union membership declined from 26 to around $16 \%$ of the private-sector workforce during the 1970 s. 
Our results also suggest that trade union politics, i.e., an articulation of common economic interests of workers against employers alone, may prove insufficient to unify workers across ethnic or religious identity divides. Dasgupta and Kanbur (2007), quoting historical examples, have argued that, instead, the provision and sharing of cultural public goods common to workers qua workers may hold the key to such unification. The present analysis further highlights this idea. ${ }^{20}$ At the same time, as Dasgupta and Kanbur (2005a) have formally shown, successful unification through contribution to common cultural public goods, which are valued independently of their income consequences, is predicated on a relative equalization of earnings across different working class identity factions. Relative equalization of access to high (social) wage employment would appear to be indispensable for such equalization of earnings. Yet, as our analysis shows, expanding employment access for an initially marginalized minority group may lead to greater ethnic conflict within the working class and consequent reduction in the overall enforcement of social wage employment. Expanding social entitlements, especially in terms of subsidized housing, health, education and cash transfers, for the marginalized group is likely to reduce ethnic conflict in the labour market and thereby improve enforcement of the social wage. However, in the absence of a prior working class identity shared across community divides, such expansions may be resisted in the electoral arena by the advanced majority of working class voters. Arguably, these dilemmas, brought into focus by our analysis, lie at the heart of the resurgence of racist and xenophobic politics in many Western countries today. ${ }^{21}$

In many developing countries, weak social entitlements appear to play a stronger role than direct market discrimination in the economic fortunes of workers from disadvantaged communities. Additionally, disadvantaged communities often constitute a plurality of the working class. In these countries, workers from disadvantaged communities often form the main support base for militant trade union movements. Our analysis suggests that the contradictions might be different in these societies. Greater social entitlements, say, through subsidized education, social housing, medical facilities, petty credit and homestead land might serve to 'demobilize' backward section dominated unions, increasing both employer evasion of the social wage and advanced section representation in

${ }^{20}$ One of the most successful early unions in the US, the Knights of Labor, provides an example. "A typical inventory of Knights-related organizations (in this case, Detroit 1885) encompassed: 'Unions, Knights of Labor assemblies, Working-men's Club Rooms, cooperative stores and factories, labor newspapers, singing societies, social clubs, political organizations, and a workers' militia(i)'. But the invention that most clearly testified to the Knights' project of forging a parallel proletarian civil society was the Knights of Labor 'Court'. ... The embryonic class culture represented by the Knights not only transcended a 'pure and simple' trade-union economism, but also provided the first alternative to dominant ethno-religious sub-cultures” (Davies, 1986: p.31). The Knights achieved a large measure of unity among Irish, German and native-born workers, as well as making a pioneering attempt to integrate Black workers. Theirs was the exception in the US. "Whereas the Western European class struggles of the 1880s and 1890s had spun a web of integrating proletarian institutions (ranging from workmen's clubs, cooperatives, and 'labor churches' to casas del pueblo and workers' educational societies), the US labor movement of the late nineteenth century ... failed to generate a workingclass 'culture' that could overcome ethno-religious alignments outside the workplace” (Davis, 1986: p. 41).

${ }^{21}$ Roemer et al. (2007) discuss the electoral consequences, of advanced workers' opposition to greater social entitlements for backward workers, in the US, UK, France and Denmark. See also Lee and Roemer (2005) and Alesina et al. (2001) for contributions on this theme. 
social wage jobs. Such demobilization in turn may lead to the political leadership of workers belonging to backward communities shifting to 'bourgeois' elements within these communities. ${ }^{22}$

Our analysis provides a general equilibrium contest-theoretic framework around which one can organize empirical studies of non-electoral forms of class and ethnic conflict in labour markets when community origins have a significant bearing on one's reservation wage. We look forward to such studies in the future. In particular, we wish to highlight one possible empirical application.

In 2005, the Indian Parliament passed the National Rural Employment Guarantee Act (NREGA). The NREGA offers up to 100 days of employment annually per rural household on public works, at some local, officially determined, minimum unskilled wage rate. It is one of the largest rights-based social protection initiatives in the world, costing about US\$2.5bn in 2006-2007. This initiative has, quite expectedly, given rise to local contestation over distribution of the rent it has generated. Activists seek to organize rural workers around the demand for employment at the official wage, while bureaucrats, politicians and contractors are routinely accused of underpayment. Simultaneously, organizations representing different caste, ethnic and religious groups in the village attempt to increase the share of their own community in available employment at the official wage. Conflicts along these two, conceptually distinct, dimensions interact and condition one another. As information regarding the initiative gradually spreads in the rural areas, such conflicts can only be expected to intensify over time. Our framework can be usefully deployed in structuring empirical investigations of the emerging pattern of social conflicts around the NREGA.

\section{Appendix}

Proof of Proposition 1. Suppose $h_{B}, h_{M}>0$. Then (5) and (7) imply $\left[\Delta_{B} g_{B}=\Delta_{M} g_{M}\right]$. Now, in a Nash equilibrium, if [for some $k \in\{M, B\}, h_{k}>0$ ], then $\left[g_{B}, g_{M}>0\right.$ ], so that (4) and (6) hold with equality, implying $\left[\Delta_{B} g_{M}=\Delta_{M} g_{B}\right]$. Since $\Delta_{B}>\Delta_{M}$, this contradicts $\left[\Delta_{B} g_{B}=\Delta_{M} g_{M}\right]$. Hence, for some $k \in\{M, B\}, h_{k}=0$. Evidently, $h_{B}=h_{M}=0$ cannot hold in equilibrium. Hence, for some $k \in\{M, B\}, h_{k}>0$. Suppose $h_{M}>0, h_{B}=0$. Then, since in equilibrium (4) and (6) must hold with equality, $\left[\Delta_{B} g_{M}=\Delta_{M} g_{B}\right]$, so that $g_{M}<g_{B}$. Since $\Delta_{B}>\Delta_{M}$, this yields $\left[\Delta_{B} g_{B}>\Delta_{M} g_{M}\right]$. However, since (7) holds with equality, (7) and (5) imply $\left[\Delta_{B} g_{B} \leq \Delta_{M} g_{M}\right]$. $\diamond$

${ }^{22}$ In India, over the last two decades, the implementation of social entitlement programs for the socalled Backward and Scheduled castes has overlapped with a weakening of traditional Communist influence in these communities, and the corresponding strengthening of caste-based groups led by their respective elites. The Communist Party of India (Marxist), India's largest Left formation, has expressed alarm. "(C)asteist forces can not only rally their supporters but also can influence a section of our supporters. ... The ordinary and poor sections of people engaged in traditional industries and agricultural sector have been with the Party because of struggles of many decades. There are attempts to draw away the basic classes who are the foundation of the Party by using casteism. Youth, women and other mass organisations are being strengthened on caste-basis. It is also attempted to extend this tendency to the trade union and agricultural sectors” (CPI(M), 2003). 
Proof of Proposition 2. From, respectively, (19), (16) and (20), and using A1, we get:

$$
\begin{aligned}
& \frac{d\left(\frac{\vec{h}_{B}}{\vec{h}}\right)}{d \Delta}=\frac{1}{2 \Delta^{2}}>0 . \\
& \frac{\partial \vec{g}}{\partial \Delta}=\frac{\Delta_{B}\left[1+2 \Delta-\Delta^{2}\right]}{2[1+\Delta]^{2} \Delta^{2}}<0 . \\
& \frac{d\left(\frac{\vec{g}_{B}}{\vec{g}}\right)}{d \Delta}=\frac{1}{(1+\Delta)^{2}}>0 .
\end{aligned}
$$

Furthermore, since $\Delta \equiv \frac{\Delta_{B}}{\Delta_{M}} \equiv \frac{W-w_{B}}{W-w_{M}}$,

$$
\begin{aligned}
& \frac{\partial \Delta}{\partial w_{B}}=\frac{-1}{\Delta_{M}}<0, \\
& \frac{\partial \Delta}{\partial w_{M}}=\frac{\Delta_{B}}{\Delta_{M}{ }^{2}}>0 .
\end{aligned}
$$

Now, noting (16),

$$
\frac{d \vec{g}}{d w_{B}}=\left[\frac{-1}{1+\Delta}\right]\left[\frac{\Delta-1}{2 \Delta}\right]+\frac{\partial \vec{g}}{\partial \Delta} \frac{\partial \Delta}{\partial w_{B}} .
$$

By (N2) and (N4), $\left[\frac{\partial \vec{g}}{\partial \Delta} \frac{\partial \Delta}{\partial w_{B}}=\frac{\left[\Delta^{2}-2 \Delta-1\right]}{2[1+\Delta]^{2} \Delta}\right]$. We thus get:

$$
\frac{d \vec{g}}{d w_{B}}=-\left[\frac{1}{(1+\Delta)^{2}}\right]<0 .
$$

Recall (16), (19) and (20). Part (i) follows from (14), (N1)-(N3) and (N5). Part (ii) is implied by (14), (N1), (N3), (N4) and (N6).

Proof of Proposition 3. Using (21) and A1, we have:

$$
\frac{\partial \vec{\pi}_{M}}{\partial \Delta}=\frac{\Delta_{B}\left(2+3 \Delta-3 \Delta^{2}\right)}{2[1+\Delta]^{3} \Delta^{3}}<0
$$

(since A1 implies: $\left[3+6 \Delta-3 \Delta^{2}<0\right]$ ). Now, using (23),

$$
\frac{\partial \vec{\pi}_{B}}{\partial \Delta}=\frac{\Delta_{B}}{4}\left[\frac{\left(5 \Delta^{3}-5 \Delta^{2}-3 \Delta-1\right)}{[1+\Delta]^{3} \Delta^{2}}\right]=\frac{\Delta_{B}}{4}\left[\frac{\left.2 \Delta^{3}+\left(3 \Delta^{3}-6 \Delta^{2}-3 \Delta\right)+\Delta^{2}-1\right)}{[1+\Delta]^{3} \Delta^{2}}\right]>0,
$$

(since, by A1, [3 $\left.\Delta^{3}-6 \Delta^{2}-3 \Delta\right]>0$; furthermore, $\Delta>1$ ). From (22):

$$
\frac{\partial \vec{\pi}_{R}}{\partial \Delta}=\frac{-\Delta_{B}}{4 \Delta^{2}}<0
$$


From (21), (N4) and (N7), and using A1,

$$
\frac{\partial \vec{\pi}_{M}}{\partial w_{B}}=\frac{-[\Delta-1]}{2[1+\Delta]^{2} \Delta^{2}}+\frac{\partial \vec{\pi}_{M}}{\partial \Delta} \frac{\partial \Delta}{\partial w_{B}}=\frac{\left(2 \Delta^{2}-3 \Delta-1\right)}{2[1+\Delta]^{3} \Delta^{2}}>0
$$

From (22), (N4) and (N9),

$$
\frac{\partial \vec{\pi}_{R}}{\partial w_{B}}=-\left[\frac{1+\Delta}{4 \Delta}\right]+\frac{\partial \vec{\pi}_{R}}{\partial \Delta} \frac{\partial \Delta}{\partial w_{B}}=-\frac{1}{4}<0 .
$$

By (N5), (N8) and (N9), $\left[\frac{\partial \vec{\pi}_{B}}{\partial w_{M}}=\frac{\partial \vec{\pi}_{B}}{\partial \Delta} \frac{\partial \Delta}{\partial w_{M}}>0\right]$ and $\left[\frac{\partial \vec{\pi}_{R}}{\partial w_{M}}=\frac{\partial \vec{\pi}_{R}}{\partial \Delta} \frac{\partial \Delta}{\partial w_{M}}<0\right]$. In light of

(N10) and (N11), Proposition 3 follows.

Proof of Proposition 4. First note that:

$$
\frac{\partial \Delta}{\partial W}=\frac{\left(w_{B}-w_{M}\right)}{\left(W-w_{M}\right)^{2}}<0 .
$$

Together, (14), (N1)-(N3) and (N12) imply our claims regarding conflict intensities and success proportions. Now, from (21), (N7) and (N12),

$$
\frac{\partial \vec{\pi}_{M}}{\partial W}=\frac{[\Delta-1]}{2[1+\Delta]^{2} \Delta^{2}}+\frac{\partial \vec{\pi}_{M}}{\partial \Delta} \frac{\partial \Delta}{\partial W}>0 .
$$

From (22), (N9) and (N12),

$$
\frac{\partial \vec{\pi}_{R}}{\partial W}=\left[\frac{1+\Delta}{4 \Delta}\right]+\frac{\partial \vec{\pi}_{R}}{\partial \Delta} \frac{\partial \Delta}{\partial W}-1=-\frac{1}{2} .
$$

From (23), (N8) and (N12),

$$
\frac{\partial \vec{\pi}_{B}}{\partial W}=\frac{\left[\Delta^{2}-1-2 \Delta\right][\Delta-1]}{4[1+\Delta]^{2} \Delta}+\frac{\partial \vec{\pi}_{B}}{\partial \Delta} \frac{\partial \Delta}{\partial W}=\frac{\Delta[\Delta-1][1-\Delta]}{[1+\Delta]^{3}}<0 .
$$

Together, (N13)-(N15) yield part yield our claims regarding distribution.

\section{References}

Alesina, A., E. Gleaser and B. Sacerdote (2001): “Why doesn’t the United States have a Europeanstyle welfare state?” Brookings Papers on Economic Activity, 2: 187-278.

Cochran, B. (1977): Labor and Communism; Princeton, University Press.

Communist Party of India (Marxist) (2003): Casteist Organizations and the Party, www.cpim.org.

Dasgupta, I. and R. Kanbur (2007): “Community and class antagonism”, Journal of Public Economics 91: 1816-1842.

Dasgupta, I. and R. Kanbur (2005a): "Bridging communal divides: separation, patronage, integration”, in C. Barrett (ed.) The Social Economics of Poverty: On Identities, Groups, Communities and Networks; London, Routledge. 
Dasgupta, I. and R. Kanbur (2005b): “Community and anti-poverty targeting”, Journal of Economic Inequality 3: 281-302.

Dasgupta, I. and S. Marjit (2006): "Evasive reform: informalization in a liberalized economy with wage-Setting unions”, in B. Guha-Khasnobis and R. Kanbur (eds.) Informal Labour Markets and Development; New York, Palgrave Macmillan.

Davis, M. (1986): Prisoners of the American Dream: Politics and Economy in the History of the US Working Class; London, Verso.

Ehrenreich, B. (2001): Nickel and Dimed: On (Not) Getting By In America; New York, Henry Halt \& Company.

Garfinkel, M. and S. Skaperdas (2007): “Economics of conflict: an overview”, in T. Sandler and K. Hartley (eds.), Handbook of Defense Economics, Vol. 2; Amsterdam, Elsevier.

Glazer, A. (2002): “Allies as rivals: internal and external rent seeking”, Journal of Economic Behavior \& Organization 48: 155-162.

Harris-White, B. (2003): India Working: Essays on Society and Economy; Cambridge UK, Cambridge University Press.

Higham, J. (1974): Strangers in the Land, New York.

Katz, E. and J. Tokatlidu (1996): “Group competition for rents”, European Journal of Political Economy 12: 599-607.

Lee, W. and J. Roemer (2005): “The rise and fall of unionized labor markets: a political economy approach”, Economic Journal 115: 28-67.

Lenin, V. (1986): “To the Jewish Workers”, in Lenin: On National Liberation and Social Emancipation; Moscow, Progress Publishers.

Lewis, W. (1954): “Economic development with unlimited supplies of labour”, The Manchester School 22: 139-191.

Roemer, J., W. Lee and K. Van der Straeten (2007): Racism, Xenophobia, and Distribution: MultiIssue Politics in Advanced Democracies; New York, Russell Sage Foundation.

Roemer, J. (1979): “Divide and conquer: microfoundations of a Marxian theory of wage discrimination”, The Bell Journal of Economics 10: 695-705.

Skaperdas, S. (1996): “Contest success functions”, Economic Theory 7: 283-290.

Trades Union Congress (2008): "Hard work, hidden lives: report of TUC Commission on Vulnerable Employment”, www.vulnerableworkers.org.uk/cove-report/full-report/

Tullock, G. (1980): “Efficient rent-seeking”, in J.M. Buchanan, R.D. Tollison and G. Tullock (eds.) Towards a Theory of Rent-Seeking Society; College Station TX, Texas A\&M Press.

Tullock, G. (1967): “The welfare costs of tariffs, monopolies, and theft”, Western Economic Journal 5: 224-232. 
